\section{ASCILITE 2021}

Back to the future
ASCILITE

SHAPING THE FUTURE OF TERTIARY EDUCATION

\title{
Design and development of a large Business School core interdisciplinary unit to foster blended learning during the Pandemic
}

\author{
Abdul Razeed, Thea Werkhoven \\ University of Sydney
}

\begin{abstract}
The paper provides a process and design overview of a large Master of Commerce unit (from hereon referred to as 'The Unit') at a University in Australia. The skills flowing from a creative and analytical mindset have been noted as crucial in the future. The Unit develops these two mindsets as complimentary by taking a multidisciplinary approach to curriculum design. By outlining the theoretical frameworks applied in the curriculum design and development and the approaches to teaching and learning, especially during the Pandemic, it is hoped that other academics and learning design teams will be able to draw inspiration that they can apply to their contexts. It is possible that the challenges that have arisen during this process may be applicable and have been experienced by other teaching teams in higher education institutions and certainly during the emergence of online learning during the Pandemic. This paper first discusses the approach we took in the curriculum design, informed by the Scholarship of Teaching and Learning (SoTL) Principles and Biggs' 3P's model of teaching and learning. The paper then focuses on design principles utilised to create the online learning management system for students.
\end{abstract}

Keywords: Multidisciplinary, SoTL, Biggs, Curriculum Development, Curriculum Design, Learning Design, Higher Education, Pandemic

\section{Introduction}

The disruption of the COVID-19 Pandemic to higher education has been widespread and challenging. When the Pandemic was at its height in 2020 in Australia, a new postgraduate unit was in the development phase for rollout in early 2021. Expected to be a large-scale unit, the subject was destined to be a flagship unit of the Master of Commerce program with the potential for a high proportion of international student enrolments. In its first iteration in 2021, approximately 2200 students had enrolled in the Unit. Of that cohort, $70 \%$ of students were enrolled remotely as a result of border closures. The majority (70\%) of students were international enrolments, and $30 \%$ were domestic students.

\section{Background of the Unit}

The overarching aim of the Unit's development was to integrate creative and analytical mindsets, which traditionally would not be considered synergistic. The multidisciplinary approach was unique as the process involved input from a large group of stakeholders, including guest lecturers, content experts, advisors, and professional staff such as educational designers and learning designers. The purpose of this approach was to encourage students to adopt various lenses when approaching content (Klaassen, 2018; Kline, 2020) and expand their ability to solve complex real-world problems through exposure to multiple disciplines (Visholm et al., 2012). As Doyle and Bozzone (2018) note, multidisciplinary higher education leads students into more critical reflection and deeper analysis, which they can contextualise and connect to real-world examples and applications.

The creative component of the course taught students how to view real-world problems from different perspectives, encouraging them to propose innovative solutions with creativity and flair. Complementary to the creative content was the analytical component of the course. Students learned how to match data analysis and visualisations to realworld problems, recognising the limitations of each type of analysis. A linking theme between all assessments and 
pedagogical content was the requirement for students to combine an analytic and creative mindset to solve realworld economic issues.

As the Unit prepares graduates to enter the economics workforce, an analysis of the skills that graduates would require in a post-pandemic world. As such, the Future of Jobs Report published by the World Economic Forum (2020) was sourced and aided in the pedagogical development of the Unit. It was appropriate for this report to have been used to reflect on the Pandemic's disruptions during 2020, looking ahead to the next five years of employability skills, technology adoption, and jobs spanning 15 industries and 26 countries worldwide.

The top 5 skills that the report identified of importance in 2020 and ahead in 2025 were: 1) analytical thinking and innovation, 2) active learning and learning strategies, 3) complex problem-solving, 4) critical thinking and analysis, and 5) creativity, originality, and initiative. These skills were integrated into the Unit's learning outcomes, assessment frameworks, rubrics, and pedagogical content.

This paper will outline the process of designing and developing the Unit, discuss the theoretical frameworks that underpinned its construction, and include reflections from staff and students.

\section{Theoretical frameworks}

Two theoretical frameworks assisted greatly in the design and development of the Unit so that it remained studentcentred, multidisciplinary, and maximised engagement during the Pandemic in a blended learning environment. These were the Scholarship of Teaching and Learning (SoTL) and Biggs' 3P's Model of Teaching and Learning (Biggs, 2003). SoTL was most helpful in guiding the curriculum design and development. Biggs' 3 P's Model helped the learning designer create an online learning environment to match pedagogical content's learning aims and structure.

The SoTL framework was appropriate for a new unit in a unique way. The framework is systematic in getting educators to reflect upon their teaching experiences to improve student learning (Institute for the Scholarship of Teaching and Learning, 2021; Potter \& Kustra, 2011). Although the Unit had not been run before, it was based on postgraduate units and their needs, challenges, and successes applicable pre-pandemic. Integrating these reflections into its creation was congruent with SoTL's complementary nature in multidisciplinary teaching and learning (Felten, 2013).

There are three main objectives of SoTL. The first objective is to improve student learning by providing a better and more engaging approach to teaching. The second objective is to foster a scholarly approach in sharing classroom practices and the effectiveness of such practices. The third objective of SoTL is to create a knowledge base through which other scholars can draw up to inform their practices (Potter \& Kustra, 2011). A focus on 'what works' also presents an academic's thought about teaching, reflecting on their observations and practice and reflecting on it after (Cruz \& Grodziak, 2021). This then feeds into a shared knowledge base called teaching commons (Huber \& Hutchings, 2006).

Hubball, Pearson, and Clarke (2013) noted that SoTL presents an approach that "internalizes theory and practice" (p.45) through "rigorous and cyclical process of inquiry" (p.45). Thus, we draw on the following questions of inquiry to inform the development of the postgrad Unit: (a) Questions about teaching including drawing on our understanding of what worked well in a blended learning environment, challenges, student engagement, pedagogy that will inform our teaching practices, what could we learn from other instructors - this links to SoTL objective 1; (b) Systematically document processes and outcomes through a detailed evaluation so that we can learn what works successfully and what doesn't so that we implement changes - this links to SoTL objective 2; and (c) Engage other academics and practitioners to share observations and lessons learned to build a knowledge base this links to SoTL objective 3 .

Hubball et al. (2013) had earlier observed that there is often an increase in disciplinary specialisation at researchintensive universities. The 'Unit' at the research university in Australia breaks away from the mold by focusing on core skill sets required by graduates rather than focused disciplinary knowledge. An inquiry into the developmental 
process of the Unit will not just extend the existing literature in the SoTL field but also makes an essential contribution to curriculum development and collective knowledge (Hubball et al., 2013).

When utilised wisely, SoTL and Biggs' 3P's Model of Teaching and Learning both allow an educator to help a student reach deeper levels of learning (Athousaki \& Luque, 2014; Kember et al., 2020). There are three interrelated phases to Biggs' Model; (1) 'Presage', (2) 'Process', and (3) 'Product' (Biggs, 2003).

During the 'Presage' phase of Biggs' Model, variables that affect student learning are noted, such as their motivations for learning, prior subject knowledge, course design, instructor presence, and the teaching context (Ng et al., 2020). In this Unit, students were not expected to have any prior knowledge of creativity or analytic mindsets. They would be present in a blended environment, with the majority taking classes remotely during the Pandemic.

Approaches to learning and how students engage with content follow in the 'Process' phase of Biggs' Model. Again, it was vital that students would receive an equitable experience with pedagogical content, workshops, assessment submission, and experience interacting with the learning management system, Canvas. These constraints helped the learning designer select appropriate tools and assets to promote learning in the course and design it in an engaging, accessible way. The final phase, 'Product', allowed the educational team to measure educational outcomes and learn through summative assessment tasks in the Unit, described in the following section of the paper.

\section{Motivations for design}

\section{Student-centered learning}

Hodges (2013) suggested that SoTL is a mindset of "questioning old assumptions about what teaching entails and how our students learn, gathering and examining evidence of the effects of our approaches, and reflecting on and sharing insights gained" (p. 72). One of the objectives of SoTL is to improve student learning by providing a better and more engaging approach to teaching. Student-centered learning provides an avenue for engaging students through resources, tools, and content and, at the same token acknowledging the students have unique learning needs (Damşa \& de Lange, 2019). The cohort of students who enrolled in this Unit was diverse. Thus to accommodate the variety of learning styles, motivations for learning, and reasons for enrolling in the subject, a student centred approach to teaching and learning was adopted as best practice (Trees, 2013).

A student-centered approach to teaching was achieved throughout assessment tasks. Students were actively engaged with tasks, guided by teaching staff but not delivering each task (Trinidad, 2019). The Unit brought together the creative and analytic mindsets but focusing on developing creative ideas, problem-solving, and utilising different data sources to develop these creative ideas further. The first half of the Unit focused on creative concepts, while the second half was on analytic concepts. Inter-related topics of the course were separated into online modules on the learning management system, Canvas. Each topic contained unique learning objectives based upon the overarching outcomes of the course. These objectives were written based on Blooms' Revised Taxonomy structure and verbs, helping them be constructively aligned with the Unit, its assessment tasks, and learning outcomes (Ali, 2018; Amer, 2006).

\section{Blended learning}

One of the objectives of SoTL is to improve student learning by providing a better and more engaging approach to teaching. With the Pandemic in full flight in 2020 and $70 \%$ of students enrolled remotely, a blended learning approach provided a more engaging platform for students to interact with the unit content. Hoffman (2018) defined blended learning as "Blended learning is a series of content blocks sequenced to create learning experiences. This is a managed, trackable curriculum with a beginning and an end" (p.1). Hoffman (2018) further exclaimed that blended learning creates opportunities for a facilitator to match learning objectives to the most appropriate delivery medium and allows learners to control where, when, and how fast they engage with the content.

\section{Learning management system}

The Canvas course was constructed to reflect a 13-week semester, with 13 modules containing weekly lecture and workshop materials and assessment and subject information. International students accessed Canvas through an 
institutional Virtual Private Network (VPN), permitting them to bypass website blocks from their home countries. This enabled them equitable access to content, akin to the level of access of a domestic student (Dhawan, 2020).

Content experts, academic partners, and teaching staff provided the learning designer with teaching content. The learning designer then assisted in chunking this content into topics or sections, matching it to complementary activities to engage students through interactivity, testing knowledge, or reflecting and interacting with one another. Traditional face-to-face lectures were replaced with short, pre-recorded videos made by the teaching team, and these were embedded into Canvas in each module. Each video was hosted through either Vimeo or Canvas Studio, permitting closed captioning toggled on or off to suit students' learning needs, in line with the 'Presage' phase of Biggs' Model.

Elements of digital design included the construction of a module template for each week's content, encapsulating content between an introductory and review page that contained learning outcomes specific to each topic. This assisted students in mapping out their progress through the Unit and made the expectations of their learning clear, also in the 'Process' phase of Biggs' Model. In addition, a common theme in design was used with formatting pages, flagging different types of content such as real-world examples, industry partner videos, and required reading lists in each module.

Assets that promoted reflection, communication, and knowledge testing were recommended and moulded by the digital learning designer, which included innate tools to Canvas and non-enterprise tools. Technological tools that were licenced for use included Genial.ly, Padlet, H5P, and Opinion Stage. These tools mirror the 'Process' phase of Biggs' Model strongly, with their selection, use, and integration closely tied to the desire for students to gain the real-world skills highlighted in the Future of Jobs report (2020). Their purpose was also to increase engagement, course interest, and interaction in the blended learning context. Constructive alignment between tools, learning outcomes, and upcoming workshops and assets was also at the forefront of the digital learning designer's priorities when constructing the site.

Genial.ly was used in the Unit to condense information into interactive images that revealed information when clicked or rolled over. This reduced the static nature of a Canvas page and helped break up chunked content. For accessibility, all text from each interactive made in Genial.ly was embedded as a PDF for students to download on the page where the interactives were located. In addition, the online collaborative tool Padlet was used when collecting opinions from students within a content page, stimulating them to interact with one another's posts in a social media style of commenting or liking.

H5P and Opinion Stage assisted in gamification of learning, quizzing students, or testing knowledge at an appropriate level for a postgraduate course. H5P allowed reflection tasks to be scaffolded into points of the course where key concepts required deeper thought or preparation for upcoming workshops. Students could be provided with content, embedded videos, or links to review and reflect, with those thoughts collected and exported to their devices as a PDF. This specific tool was selected as students' reflections were not sent to the teaching team through Canvas, giving them autonomy and responsibility in progressing through content at their own pace. The H5P tool also allowed embedded questions in various formats, including multiple-choice, drag and drop or fill in the word to be put into the pages sporadically, mirroring upcoming summative assessments with immediate feedback on the right/wrong answers. Opinion Stage was similar in its use to the quizzing function of H5P, with a different interface and displayed to students when embedded into the page. However, this tool benefited the learning designer to construct case study style quiz sets with complementary copyright-friendly images, making pages visually attractive and engaging to students.

\section{Reflection tasks}

We built several reflection activities through the module and an overall reflective task (see assessments). Liu (2019) found in her examination of how weekly reflection and questioning instructional methods affected learners' learning in an online graduate class in the USA that reflection and questioning techniques effectively engaged and challenged online graduate learners. In the same vein, to foster better student engagement, we designed several reflective tasks to pause and gather their thoughts on what they have learned. We also created an assessment that allowed students to reflect on the creative and analytic contents by setting up a template developed through a review of Rolfe et al.

(2001), Kolb (2014), Ryan and Bourke (2013), and Roberts (2020). 
Reflection tasks in the Unit were designed in line with Biggs' model, whereby links between reflection tasks and upcoming workshop tasks were laid out clearly to students. This linkage was designed to help them understand the importance of the skill in both the professional environment and forthcoming workshops and assessments. The underpinning goal of this decision is to promote deeper learning, identified to take place when the model is applied with a well-designed curriculum and plentiful teacher-student and student-student interaction (Kember et al., 2020).

\section{Assessment}

The blended learning approach called for a series of content blocks sequenced to create learning experiences. With creativity and analytics as the mindsets covered in the Unit, the development team set up a series of assessment tasks that guided the learner to set up a creative problem which can then be developed into a business case in the analytics part of the Unit. Assessment tasks in the Unit were designed to challenge students' comprehension so that they not only focused on attaining knowledge for scholarly outcomes but also so that they were stimulated towards deeper learning - a link that mimicked that between the process and product phases of Biggs' model (Biggs, 2003).

Each assessment task was modeled on the appropriate learning outcomes or objectives, with a thorough marking rubric available for all students upfront. To promote students to be actively engaged with their learning, each primary assessment was scaffolded progressively. Students utilised their data to create a business proposal, mirroring a real-world scenario. This approach of sequencing and integrating assessment tasks into a unit has fit well with the process and product phases of Biggs' 3P's model in higher education (Duan \& Qi, 2014). The structure of course content integrated with the assessment tasks of the Unit, whereby the assessment feedback provided to students at each stage fed forward to upcoming tasks and helped to ensure constructive alignment between course outcomes and assessment task criteria (Meyers \& Nulty, 2009). There were $60 \%$ individual and $40 \%$ group weight on assignments. The weighting was deliberate to enable students to engage in the content, challenge the notions of their level of creativity and familiarity with analytics and reflect on the unit content. These are hallmarks of active learning (Rotgans \& Schmidt, 2011).

Similar to the real world, students had to complete tasks in groups and rate the participation of their fellow group members. Students were required to demonstrate skills in the rubrics for each assessment linked back to improving their employability through authentic assessment (Sokhanvar et al., 2021). Villaroel et al. (2017) identified three concepts critical to authentic assessment: the realism of a task, the degree of cognitive challenge, and evaluative judgment required. By asking students to collaborate in groups, complete a series of individual or group video tasks and critically reflect and evaluate themselves. One another, the three concepts identified by Villaroel et al. were achieved. In addition, the use of submission through an online platform and submission of a shared video format enabled a more innovative online learning environment for students, taking them out of their comfort zone of the traditional document upload (Herrington, 2006).

\section{Workshop design}

The workshops were two hours in duration. They were designed to allow students to ask questions from previous weeks' content and activities, engage in a series of hands-on activities, provide an opportunity for students to reflect on the activities covered in the workshop, and finally for the groups to come together to connect, support each other and develop the group business case. In particular, connecting with what students feel is vital for their engagement in their learning process and mental and physical health (Cruz \& Grodziak, 2021).

Cruz and Grodziak (2021) also note that fostering a sense of connection does not just stop with students. Reflecting and sharing teaching and learning practices creates a shared experience of teaching and learning in 2020. They argue that such a vehicle is congruent with SoTL principles, encouraging teachers to share their experiences to support others through challenges such as the Pandemic. Once again, it is with this spirit that this paper details our rationale for the activities and the design process.

Akin to the process phase of Biggs' model of teaching and learning where students can either move towards the surface or deeper levels of learning, workshops were designed to enhance students' understanding of key concepts by permitting them to work through problems and case studies (Kanashiro et al., 2020). This skill was key to upcoming assessment tasks, reflecting an overarching link between Biggs' model's process and product phases. The 
workshops were also designed with several activities based on sound research underpinnings. For example, to foster creativity, we drew on activities that have been proven to encourage engagement in creativity. For analytics, we used data that was authentically drawn from scientific research (Kjelvik \& Schultheis, 2019).

\section{Guest lectures and real-world examples}

As noted earlier, the content was built by providing short and sharp 10-minute lectures that developed and supported some of the more challenging concepts covered in the modules. Ten minutes is seen as ideal to engage students effectively (Richardson, 2010). Therefore, the 10-minute lectures were recorded by the content experts developing the particular module. In addition, a brief, media-produced video signposted the beginning of each topic that the unit coordinator recorded to introduce students to the upcoming content. This scaffolded the content and is known to enhance student recall of video lecture content, and as such, each video introduced critical concepts for each topic (Fanguy et al., 2017).

We had many international students who have had no domain knowledge of many of the concepts covered in the Unit. As such, we recorded guest lectures. This provided all students background knowledge which is vital to progress their understanding further. In addition, these recordings aimed to relate the course contents to industry and the real world, inspire students, and boost their engagement with course content (Krogstie \& Krogstie, 2018). The guest lecturer videos were recorded and delivered by industry practitioners who related critical concepts from each topic to their professional endeavours.

\section{Collaboration}

To encourage students to explore their creativity, a collaboration was undertaken with a local museum. The local museum allowed us to create a space for students to explore their creativity and link this back to the analytics behind the museum objects. The museum thus created an ideal environment to connect creativity and analytics. Together with museum staff, we designed an Object-Based Learning (OBL) workshop. OBL is a student-centered approach supporting acquiring subject-specific skills and cross-disciplinary knowledge, among other transferable skills (Chatterjee \& Hannan, 2016). Students interacted with artifacts through object-based learning (OBL), stimulating thinking on related topics (Frost, 2013).

Additionally, to further reinforce the multidisciplinary nature of the Unit, a collaboration was initiated with library staff who supported the university's academics and students from a wide range of disciplines. Students were asked to submit questions to this multidisciplinary panel to seek support in developing their group assignment. In addition, video feedback was provided to students to foster a personal connection to students, especially during the Pandemic (Mahoney et al., 2019). Supporting students in this way was in line with Biggs' model's product phase, setting them up with resources and assistance that they could benefit from if they utilised fully (Biggs, 2003).

\section{Reflections}

\section{Challenges}

From the learning designers' perspective, challenges of the design and development of the Unit were ensuring that there was pedagogical strength behind the selection and implementation of learning tools throughout the course and attempting to create engaging and stimulating assets without extensive content knowledge. The digital learning designer managed these to test the assets and request feedback from the teaching team, continually modifying their wording/phrasing/formatting based on their evaluations. In this way, the Unit underwent a series of iterations before it was released to students, including reviews from the digital learning designer mimicking the student view and utilising a digital design checklist.

\section{Successes}

The Unit achieved a satisfaction rating of over $80 \%$. Feedback collected as part of a unit survey indicated that students valued the Unit greatly. It allowed them to explore their creative and analytical skills rather than focus on discipline knowledge. Several students commented that they valued how they had to critically question their creative 
idea and evaluate the appropriateness of the data they had to collect. Hence, they saw the usefulness of critical thinking. Students also commented that while the Unit challenged them, they felt supported in their learning through the learning management system, feedback, academics, and peer support. Many students commented that they saw the value of creative, critical, and analytical thinking for their future careers.

Additionally, students noted that short lecture videos, short videos on real-world examples, drag and drop activities, typing answers into a box, checking your understanding activities, and infographics diagrams helped them in their learning. Additionally, over $78 \%$ of students acknowledged that Canvas provided them opportunities for interactivity, and $68 \%$ of students pleasingly provided feedback that the canvas activities allowed them to connect with other students (through discussion forums, for example). Given an option to have a traditional lecture or a blended learning platform like those presented in the Unit, $68 \%$ preferred the blended learning platform. $87 \%$ of students acknowledged that the reflective tasks within the Unit helped them actively engage with the content in the Unit. Over $92 \%$ also felt that the content learning management system was reinforced in the workshop. The majority of students (68\%) also acknowledged the value of the collaborations in their unit engagement.

\section{Room for improvement}

Several students commented that they want to be better supported in developing their assessments. This message also came through in the feedback that we sought from fellow academics and tutors. Some students felt that the space of one semester provided them limited opportunities to pursue a creative idea that they were genuinely keen on.

The feedback from tutors and fellow academics also provided us with valuable feedback. The focus in this instance was more on pedagogy and the improvements in assessment design that will further support students. One of the outcomes of our discussion is that students need to be guided further on how to form and develop a creative question.

\section{Conclusions and recommendations}

The paper provided a process and design overview of a large Master of Commerce unit (here on referred to as 'The Unit') at a University in Australia. Creative and Analytical mindsets were flagged as crucial skills of the future. The paper outlined the development of the Unit through a focus on the guiding principles put forward by the SoTL and Biggs' 3P's frameworks.

We were genuinely pleased to learn that students saw the value in a skills-based Unit that developed their critical, creative, and analytical skills. On the other hand, with only a semester to be acquainted with the many creative and analytical concepts and marry these, students wanted greater support in developing their innovative ideas and finding relevant data to advance their creative idea. The academics involved in the Unit are now actively looking at ways to best support students through many avenues, including learning content directed at identifying creative ideas and supporting students in identifying relevant data early in the teaching semester.

Fanghangel (2013) and Felten (2013) noted that SoTL advocates iterative guidance in addressing teaching and learning practices. The goal of this inquiry is not about producing definitive solutions but instead opening up new lines of inquiry (Brew, 2002). We have many questions to answer and more to ask, but this is congruent with other SoTL scholars' practices (Cruz \& Grodziak, 2021).

The effects of Covid have accelerated the need to connect and share (Cruz \& Grodziak, 2021). As a result, crossdisciplinary collaboration is gaining momentum and a more extensive feed into the repository of teaching practices.

In conclusion, we would like to draw on the words of Cruz and Grodziak (2021):

Rather than despair of our current situation, we should perhaps be proud of the fact that, through the darkest hours of modern academic history, we have sustained, and been sustained by, a love of teaching, care for our students, and the belief that higher education matters (p.9). 


\section{References}

Ali, L. (2018). The Design of curriculum, assessment, and evaluation in higher education with constructive alignment. Journal of Education and e-learning research, 5(1), 72-78.

Amer, A. (2006). Reflections on Bloom's revised taxonomy. Electronic Journal of Research in Educational Psychology, 4(1), 213-230.

Athousaki, R., \& Luque, N. E. (2014). Reflections on developing a pilot scholarship of teaching and learning (SoTL) project for aviation with the use of an airline simulation activity. Aviation Management Conference, Amsterdam, The Netherlands.

Biggs, B. (2003). Teaching forquality learning at university: What the student does (2nd ed.). Society for Research into Higher Education.

Brew, A. (2002). The Nature of Research: Inquiry in Academic Contexts. Routledge.

Chatterjee, H. J., \& Hannan, L. (2016). Engaging the senses: Object-based learning in higher education. Routledge.

Cruz, L. E., \& Grodziak, E. M. (2021). SOTL under Stress: Rethinking teaching and learning scholarship during a Global Pandemic. Teaching \& Learning Inquiry, 9(1), 3-13. https://doi.org/https://doi.org/10.20343/teachlearninqu.9.1.2

Damşa, C., \& de Lange, T. (2019). Student-centred learning environments in higher education. Uniped, 42(01), 926. https://doi.org/https://doi.org/10.18261/issn.1893-8981-2019-01-02

Dhawan, S. (2020). Online learning: A panacea in the time of COVID-19 crisis. Journal of Educational Technology Systems, 49(1), 5-22. https://doi.org/https://doi.org/10.1177/0047239520934018

Doyle, M., \& Bozzone, D. (2018). Multidisciplinary teaching providing undergraduates with the skills to integrate knowledge and tackle "Big" questions. The Journal of the Center for Interdisciplinary Teaching \& Learning, 7(1), 12-17.

Duan, J., \& Qi, Y. (2014). An online curriculum design framework based on 3P model from the perspective of knowledge transfer. 2014 9th International Conference on Computer Science \& Education.

Fanghanel, J. (2013). Going public with pedagogical inquiries: SoTL as a methodology for faculty professional development. Teaching and Learning Inquiry, 1(1), 59-70. https://doi.org/https://doi.org/10.2979/teachlearninqu.1.1.59

Fanguy, M., Costley, J., \& Baldwin, M. (2017). Pinch hitter: The effectiveness of content summaries delivered by a guest lecturer in online course videos. International Review of Research in Open and Distributed Learning, 18(7). https://doi.org/https://doi.org/10.19173/irrodl.v18i7.3208

Felten, P. (2013). Principles of good practice in SoTL. Teaching and Learning Inquiry, 1(1), 121-125. https://doi.org/https://doi.org/10.2979/teachlearninqu.1.1.121

Frost, O. C. (2013). When the Object is Digital: Properties of Digital Surrogate Objects and Implications for Learning. In R. Parry (Ed.), Museums in a Digital Age. Routledge.

Herrington, J. (2006). Authentic e-learning in higher education: Design principles for authentic learning environments and tasks. E-Learn: World Conference on E-Learning in Corporate, Government, Healthcare, and Higher Education, Montreal, Quebec, Canada.

Hodges, L. C. (2013). Postcards from the edge of SoTL: A view from faculty development. Teaching and Learning Inquiry, 1(1), 71-79.

Hofmann, J. (2018). Blended learning. American Society for Training and Development Press.

Hubball, H., Pearson, M. L., \& Clarke, A. (2013). SoTL inquiry in broader curricular and institutional contexts: Theoretical underpinnings and emerging trends. Teaching and Learning Inquiry, 1(1), 41-57. https://doi.org/https://doi.org/10.2979/teachlearninqu.1.1.41

Huber, M. T., \& Hutchings, P. (2006). Building the teaching commons. Change: The magazine of higher learning, 38(3), 24-31. https://doi.org/https://doi.org/10.3200/CHNG.38.3.24-31

Institute for the Scholarship of Teaching and Learning. (2021). Scholarship of Teaching and Learning (SoTL). The University of British Columbia,. Retrieved 20 June 2021 from https://isotl.ctlt.ubc.ca/about/sotl/

Kanashiro, P., Iizuka, E. S., Sousa, C., \& Dias, S. E. F. (2020). Sustainability in management education: a Biggs' 3P model application. International Journal of Sustainability in Higher Education. https://doi.org/https://doi.org/10.1108/IJSHE-05-2019-0176

Kember, D., Webster, B. J., \& Chan, W. S. (2020). Refocusing the 3P model to incorporate a learning and teaching environment and graduate attributes. Educational Psychology, 40(5), 592-607. https://doi.org/https://doi.org/10.1080/01443410.2020.1732304

Kjelvik, M. K., \& Schultheis, E. H. (2019). Getting messy with authentic data: Exploring the potential of using data from scientific research to support student data literacy. CBE-Life Sciences Education, 18(2), es2. https://www.ncbi.nlm.nih.gov/pmc/articles/PMC6755219/pdf/cbe-18-es2.pdf 
Klaassen, R. G. (2018). Interdisciplinary education: a case study. European Journal of Engineering Education, 43(6), 842-859.

Kline, S. J. (2020). Conceptual foundations for multidisciplinary thinking. Stanford University Press.

Kolb, D. A. (2014). Experiential learning: Experience as the source of learning and development. FT press.

Krogstie, B. R., \& Krogstie, J. (2018). Guest lecturers in education: Recommendations based on an empirical study. Norsk konferanse for organisasjoners bruk at IT, Norway.

Liu, Y. (2019). Using reflections and questioning to engage and challenge online graduate learners in education. Research and Practice in Technology Enhanced Learning, 14(1), 1-10. https://doi.org/https://doi.org/10.1186/s41039-019-0098-Z

Mahoney, P., Macfarlane, S., \& Ajjawi, R. (2019). A qualitative synthesis of video feedback in higher education. Teaching in Higher Education, 24(2), 157-179. https://doi.org/https://doi.org/10.1080/13562517.2018.1471457

Meyers, N. M., \& Nulty, D. D. (2009, 2009/10/01). How to use (five) curriculum design principles to align authentic learning environments, assessment, students' approaches to thinking and learning outcomes. Assessment \& Evaluation in Higher Education, 34(5), 565-577. https://doi.org/10.1080/02602930802226502

Ng, B., Tan, S. C., Quek, C. L., Looker, P., \& Koh, J. (2020). Exploring the relationships of factor measures in Blended learning environments. In Transforming Teaching and Learning in Higher Education (pp. 205223). Springer.

Potter, M. K., \& Kustra, E. (2011). The relationship between scholarly teaching and SoTL: Models, distinctions, and clarifications. International journal of Scholarship of Teaching \& Learning, 5(1). https://doi.org/https://doi.org/10.20429/ijsotl.2011.050123

Richardson, H. (2010). Students only have '10-minute attention span'. Retrieved June 202021 from http://news.bbc.co.uk/2/hi/uk news/education/8449307.stm

Roberts, W. (2020). Reflections on practice during a pandemic: How do we continue to ensure effective communication during the COVID-19 Pandemic? Child Abuse Review (Chichester, England: 1992), 2020(10). https://doi.org/https://doi.org/10.1002/car.2660

Rolfe, G., Freshwater, D., \& Jasper, M. (2001). Critical reflection for nursing and the helping professions a user's guide. Palgrave Macmillan.

Rotgans, J. I., \& Schmidt, H. G. (2011). The role of teachers in facilitating situational interest in an active-learning classroom. Teaching and teacher Education, 27(1), 37-42. https://doi.org/https://doi.org/10.1016/j.tate.2010.06.025

Ryan, M., \& Bourke, T. (2013). The teacher as reflexive professional: Making visible the excluded discourse in teacher standards. Discourse: Studies in the cultural politics of education, 34(3), 411-423. https://doi.org/https://doi.org/10.1080/01596306.2012.717193

Sokhanvar, Z., Salehi, K., \& Sokhanvar, F. (2021, 2021/09/01/). Advantages of authentic assessment for improving the learning experience and employability skills of higher education students: A systematic literature review. Studies in Educational Evaluation, 70, 101030. https://doi.org/10.1016/j.stueduc.2021.101030

Trees, K. (2013). Effectively Teaching Diverse Student Groups: A reflection on teaching and learning strategies. Australian Journal of Adult Learning, 53(2), 234-252. https://doi.org/https://doi.org/10.3316/aeipt.199186

Trinidad, J. E. (2019, 2020/09/13). Understanding student-centred learning in higher education: students' and teachers' perceptions, challenges, and cognitive gaps. Journal of Further and Higher Education, 44(8), 1013-1023. https://doi.org/10.1080/0309877x.2019.1636214

Villarroel, V., Bloxham, S., Bruna, D., Bruna, C., \& Herrera-Seda, C. (2017, 2018/07/04). Authentic assessment: creating a blueprint for course design. Assessment \& Evaluation in Higher Education, 43(5), 840-854. https://doi.org/10.1080/02602938.2017.1412396

Visholm, A., Grosen, L., Norn, M. T., \& Jensen, R. L. (2012). Interdisciplinary research is key to solving society s problems (DEA, Copenhagen. Interdisciplinarity and sustainability: shaping futures, Issue. https://www.datocms-assets.com/22590/1586461539-summary-report-interdisciplinary-research-is-key-tosolving-society-s-problems.pdf

World Economic Forum. (2020). The Future of Jobs Report 2020. 
Razeed, A., \& Werkhoven, T. (2021). Design and development of a large Business School core interdisciplinary unit to foster blended learning during the Pandemic. In Gregory, S., Warburton, S., \& Schier, M. (Eds.), Back to the Future-ASCILITE '21. Proceedings ASCILITE 2021 in Armidale (pp. 257-

266). https://doi.org/10.14742/ascilite2021.0138

Note: All published papers are refereed, having undergone a double-blind peer-review process.

The author(s) assign a Creative Commons by attribution licence enabling others to distribute, remix, tweak, and build upon their work, even commercially, as long as credit is given to the author(s) for the original creation.

(C) Razeed, A., \& Werkhoven, T. 2021 